\title{
Experiences of disadvantaged African-Canadian migrants in Ontario, Canada
}

\author{
Kon K Madut* \\ University of Ottawa, Canada
}

This article provides a sociological analysis of the disadvantaged African Canadian migrants' experiences and challenges of the integration process in the province of Ontario. In this qualitative study, migrants discussed the challenges of resettlement, livelihood, health, and social well-being from their perspectives. They shared their personal experiences with housing, health services, lack of work, and access to social support services. Data used in this research come from transcribed stories gathered through intensive one-on-one interviews with 26 African Canadian migrants, each lasting 1-2 hours, and three focus groups with 30 others. The 56 participants in the study were recruited from three Ontario cities of Ottawa, Toronto, and Kitchener. The survey covered the period from March 2013 to October 2017. Using the grounded theory (GT) method, interviews were transcribed, coded, categorised, and analysed using NVivo 10. In this study, participants have shared their experiences with racism and discrimination, and most have cited lack of access to adequate social programs, employment support, and resettlement services as the most significant barriers to meaningful social and economic integration. They reiterated the importance of employment support and social services programs tailored toward migrants' needs with an emphasis on socio-political, cultural, and economic integration.

Key Words: African diaspora, migration, integration, resettlement, social well-being

Article Info: Received: Fanuary 2, 2019; Revised: April 24, 2019; Accepted: May 16, 2019; Online: May 31, 2019.

\section{${ }^{*}$ Correspondence address}

Address: 75 Laurier Avenue East, Ottawa ON K1N 6N5, Canada

Phone: +613-562-5700 | Email: Kmadut@uottawa.ca

(C2019 Human Geographies; The authors

\section{(2) $\stackrel{\leftrightarrow}{r}$ This work is licensed under a}

Creative Commons Attribution 4.0 International License. DOI:10.57 19/hgeo.2019.131.4 


\section{Introduction}

The challenges facing African migrants in Ontario date back to the inception of Canada in 1867, when immigration from Africa was nearly eliminated by the Canadian policymakers. From 1946 to 1960, African migrants represented only $0.3 \%$ of the total number of new arrivals to Canada (Mullings et al., 2016). The improvement of immigration policies in 1966 and the adoption of the Human Rights Act has increased the number of Africans coming to Canada, especially Nigerians and Ghanaians (Mullings et al., 2016). This improvement includes the family class sponsorship aimed at helping Africans to sponsor family members to join them in Canada. The family class sponsorship has increased the number of African migrants from Tanzania, Kenya, Angola, and Zimbabwe (Schroeter \& James, 2015). Most recently, globalisation and technological advancements have also contributed to bringing in Africans who come to the country as skilled workers and refugee claimants (Madut, 2016). This study incorporates empirical data obtained through interviews to assess current views and perspectives of African migrants using their own stories and suggests the way forward to improved policies.

\section{The African-Canadians in Ontario}

For decades, the overall contribution of the African Canadians in the province of Ontario and the challenges they endured socially, politically, and economically have been ignored, or have not been treated as a matter of public policies of socioeconomic development. In 2001, the province of Ontario hosted about 175,000 African Canadians, equivalent to about 2\% of its population (Statistics Canada, 2007). Nonetheless, African Canadian experiences with challenges related to resettlement and livelihood in Canada have been overlooked, as they were treated as a part of the so-called visible minority Canadian population. For example, $50 \%$ of African Canadians had experienced discrimination or unfair treatment based on their ethnicity, race, religion, language, or accent. In this context, $87 \%$ of African Canadians who had experienced discrimination sensed that it was because of their race or skin colour, and $62 \%$ reported that the bias occurred in the process of applying for a job or promotion at the workplace (Statistics Canada, 2007). Even within this category of "African Canadian", we can find that the narratives of the experience are the same when it comes to social injustices, but all African communities experience it differently. For example, the African Canadian community is over-represented in the criminal justice system and the Child Welfare System (CWS) in Ontario (Ontario Human Rights Commission, 2018) due to the lack of opportunities and weak labour market outcomes for youth and their parents. Statistics Canada (2007) further revealed: 'As with the overall population, young African people experience relatively high unemployment rates. In 2001, $21 \%$ of all male African labour force participants aged 15 to 24 were unemployed, well above the data (14\%) for all Canadians males 
in this age range. At the same time, $20 \%$ of African female labour force participants aged 15 to 24 were unemployed, whereas the figure for the overall female population in this age range was 13\%.' (Para. 8)

Unemployment coupled with social exclusion is the main cause of the overrepresentation of young African Canadians in Canadian jails and prisons. The provinces of Alberta, Manitoba, and Ontario have witnessed an increase in the number of African youth that comes in contact with the justice system due to the difficulties in securing meaningful employment and access to training with employment prospects in the local labour market. However, the East African youth in Alberta and Manitoba are the most affected by this issue (Statistics Canada, 2007). The majority of African Canadians take on entry-level jobs in service sectors even though they hold higher education credentials and possess relevant work experience obtained before migrating to Canada (Statistics Canada, 2007). Statistic Canada (2006) further reported that 'African Canadians are more than twice as likely as those in the overall population to have low incomes' (Para. 12). For example, in 2000, $39 \%$ of the African population in Canada had incomes below low-income cut-off (LICO), compared with $16 \%$ of the overall Canadian population. In addition, they are more likely to experience unemployment within the Canadian labour force.

Statistics Canada (2006) has calculated the unemployment rate among the African labour force participants as $13.1 \%$ in 2001, compared to $7.4 \%$ among all labour force participants. Ironically, these cycles of poverty among African Canadians continue to their retirement and well into old age. Specifically, in 2000, $60 \%$ of African Canadian seniors aged 65 and over living on their own in Ontario had incomes below the LICO, 20\% higher than all seniors living on their own. Moreover, $64 \%$ of African Canadian women had incomes below the LICO, compared with $54 \%$ of senior African men and $43 \%$ of all women aged 65 and over in the province (Statistics Canada, 2006).

First-generation African Canadian migrants placed hope on their children to succeed in a country in which they found it almost impossible to adapt, settle, and integrate socially, politically, and economically due to the blatant systemic discrimination, marginalisation, and social isolation wherever they decided to settle within the country. Consequently, in 2000, $47 \%$ of African children aged 15 lived in low-income families, compared with $19 \%$ of all children in Canada (Statistics Canada, 2007). Many have considered government-subsidised housing as an affordable environment that helps families with the high cost of the housing market rent. It is also thought of as a place that would allow their children to meet with peers, who often encourage them to participate in illegal activities in order to satisfy needs that their parents cannot provide (Creese, 2018).

For African Canadians, coming to Canada was not only about escaping wars and human rights abuse, and living in a peaceful country with an excellent record of human rights, but also a new home with great potential to thrive, raise a family, and support the extended family back home. For these reasons, they have developed a strong sense of belonging to Canada. 


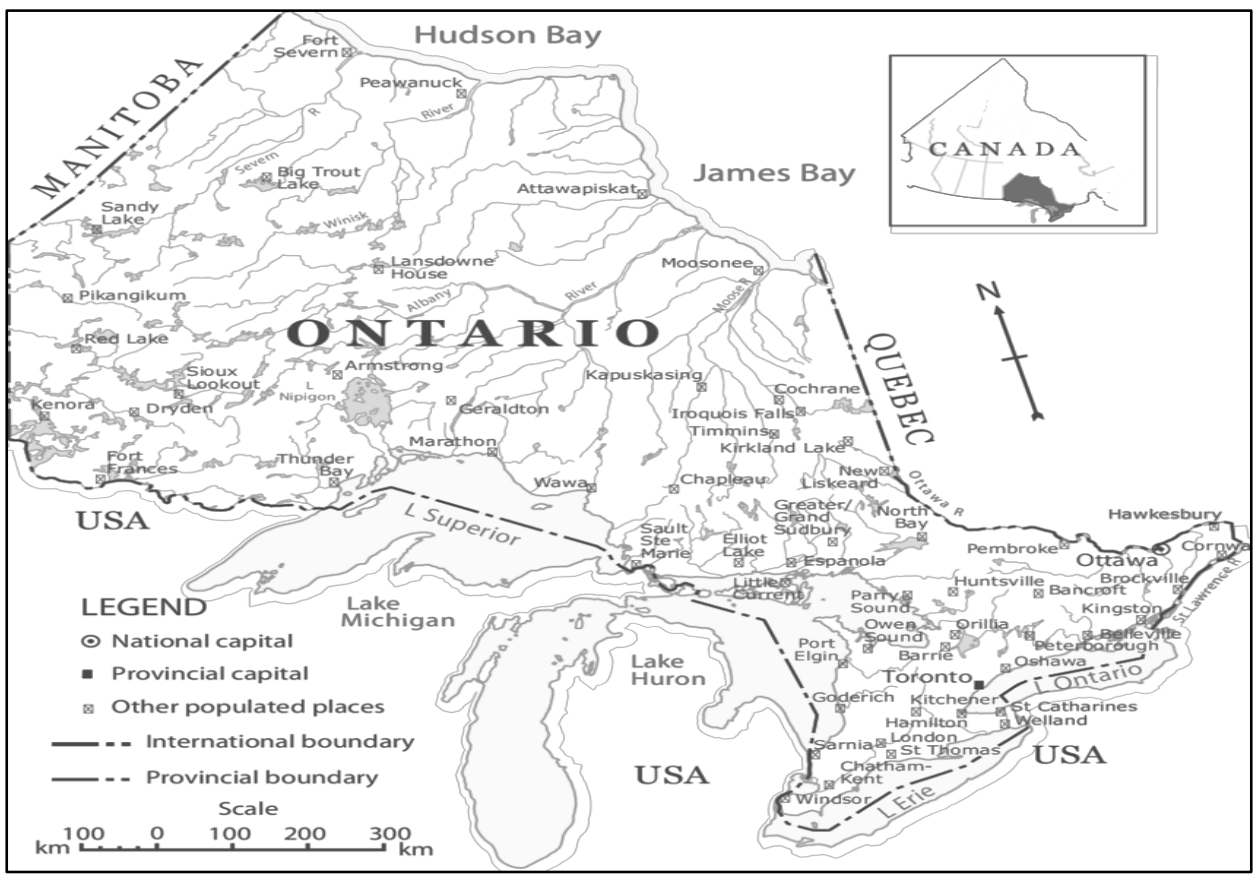

Figure 1. Ontario counties and townships

Source: Global Genealogy (1992)

According to the Ethnic Diversity Survey (EDS), 83\% of participants of African origin said that they had a strong sense of belonging to Canada, and $71 \%$ retained a strong sense of belonging to their ethnic or cultural group (Statistics Canada, 2005). Nonetheless, African Canadians have always been active in Canadian society. The EDS (2002) reported that $66 \%$ voted in the 2000 federal election, $60 \%$ voted in the last provincial election, and $48 \%$ had participated in a sports team or a community association in the 12 months preceding the survey (Statistics Canada, 2005).

\section{Black population in Ontario}

According to Statistics Canada (2019), 53.4\% of the total Black population in Ontario in 2016 were first-generation migrants. The second-generation comprised $38.4 \%$ of the entire Black community in Ontario, while the thirdgeneration numbered $8.3 \%$. Even though Blacks in Ontario Canada come from 150 different countries, about one-half were born in the Caribbean, with Jamaica as the leading source country in the region, followed by Nigeria, Trinidad and Tobago, Somalia, Ghana, and Ethiopia (Statistics Canada, 2019). The Black newcomers represented $14.1 \%$ of all Black migrants in Ontario numbered between 2011 to 2016 period. Most of these newcomers reported Jamaica, Nigeria, Haiti, and Ethiopia as their country of birth (Statistics Canada, 2019).

Further, the Black population in Ontario have reported more than 200 ethnic and cultural origins, and $80 \%$ reported English as their mother tongue, while $6 \%$ 
reported French. Somali, Akan (Twi), and Amharic were the other most frequently reported mother tongues by the Black population in Ontario (Statistics Canada, 2019). These unique contributions of Black migration to the Ontarian socioeconomic and cultural heritage are not effectively utilised as a part of the Canadian multicultural mosaic. Black migrants continue to endure all forms of physical abuse and systemic institutionalised discrimination, including police brutality, harassment, and sociocultural and economic marginalisation (Mullings et al., 2016). Indeed, social and institutionalised discrimination against the Black migrants is one of the most unsettled social biases against minorities in Canada that hinders the integration outcomes of these migrants in Ontario and Canada at large (Madut, 2016).

\section{Overall experiences of the racialised migrants}

Ethnic migrants face many challenges during the process of integration and resettlement, which has been well documented by scholars and policymakers nationwide. The purpose of this article, however, is to explore these challenges as discussed by migrants from their perspectives. The reports by the Social Planning Council of Ottawa (2009) and Statistics Canada provided a background illustration of the racialised minority participation in local socioeconomic development and attainment. The mentioned reports are based on studies conducted between 2001 and 2006 to evaluate the success of the economic integration of the racialised minority immigrants in the local labour market. The findings indicated that the racialised minority population in Ottawa had experienced $22.3 \%$ growth, and immigrant contribution in the local labour market was about $79 \%$.

The report also indicated that $75.1 \%$ of recent immigrants were racialised minorities and that $38.8 \%$ of the racialised migrant populations in Ottawa were not immigrants. Further, 63.2\% of racialised migrants in the 2001-2006 period were youth aged 15-24 years. Refugees comprised $17.9 \%$ of residents, and the labour force participation rate among the racialised migrants was $67.6 \%$, with an employment rate of $60.3 \%$ and an unemployment rate of $10.8 \%$. Some 1,650 recent immigrants left Ottawa for another destination in the period covered by this report (Statistics Canada, 2006). According to the study conducted by the Social Planning Council of Ottawa (2009), the City of Ottawa was the recipient of the most highly educated migrants admitted to Canada in 2006. About $52 \%$ of the population aged 25 to 64 had a university degree. The study also revealed that about $66.4 \%$ of the newly arrived migrants (in the 2001-2006 period) to the City of Ottawa were holders of post-secondary graduate level education (Social Planning Council of Ottawa, 2009).

These challenges of socio-economic integration and the high rate of unemployment and underemployment among racialised immigrants were also discussed in a study conducted by Steward (2010). The author identified five essential themes that revealed racialised migrants' frustration with unemployment, namely anxiety, deep-rooted inequality, rejection, crushing 
personal and household debt, and lack of government intervention. For example, Statistics Canada (2006) indicated that, among the $84 \%$ of the general population who have post-secondary education in Ottawa, 53.8\% were immigrants, yet they cannot secure meaningful employment. Further, in 2006, about $46 \%$ of the total number of migrants received their education within Canada, and $84.4 \%$ of recent immigrants gained their post-secondary qualifications outside Canada, a group known as foreign-trained professionals or FTPs (Statistics Canada, 2006).

The Social Planning Council of Ottawa (2009) has also reported that the highest proportion of the recent racialised migrants coming to Ottawa had postsecondary qualifications. These top credentials are not reflected in the types of jobs these individuals were able to obtain, despite their over-representation in the local labour force. As such, their unemployment rate remained at $18 \%$, especially among recent immigrants aged 15-24, and 13\% among recent migrants aged 25 and older. This percentage is comparable to a typical unemployment rate during the 1933 collapse into the Great Depression (Statistics Canada, 2006).

Policymakers have tried to understand, discuss, and meet the challenges of settlement and integration issues among racialised migrants in Canada by using statistical analyses and by presenting quantitative data on skills, levels of participation, and contributions made by these migrants in cities in which they settle. These reports, published annually, tend to state redundancies regarding participation, qualifications, and types of jobs racialised migrants are typically able to obtain within the Canadian labour market (Madut, 2016).

However, these reports have not addressed the concern of the majority of the racialised migrants who strive for jobs that meet their needs and career aspirations and promote their health and social well-being. Nonetheless, among all the major cities in Canada, Ottawa has remained the first-choice home for the highly skilled and educated racialised migrants due to the concentration of governments and diplomatic missions in this city (Hou, 2004). Ottawa is home to three levels (municipal, provincial, and federal) of government, and thus a significant local employer. The Statistics Canada (2006) report also indicates that the demographics of the migrants have continued to change with the new point system, which gives precedence to the highly educated migrants relative to vocationally trained individuals. Since the increased number of highly educated racialised immigrant workers is not properly utilised, the practice is perceived by these migrants as an indication of systematic discrimination (Beach et al., 2011). Further, these meth-ods had a severe negative impact on the potential socioeconomic development of Canada, given that significant human resource capabilities of racialised migrants were not being used for the benefit of the country as intended (Beach et al., 2011).

Within this discourse of the racialised migrants in Canada, the case of racialised African Canadians is unique and not well understood by policymakers, researchers, and resettlement workers. Thus, there is a need to explore and discuss the issues of integration and resettlement among these groups from their perspectives. That way, what is being said can stand alongside what it is not and 
can help understand the perceptions of the racialised African migrants, as well as the factors that aided in the development of these perceptions.

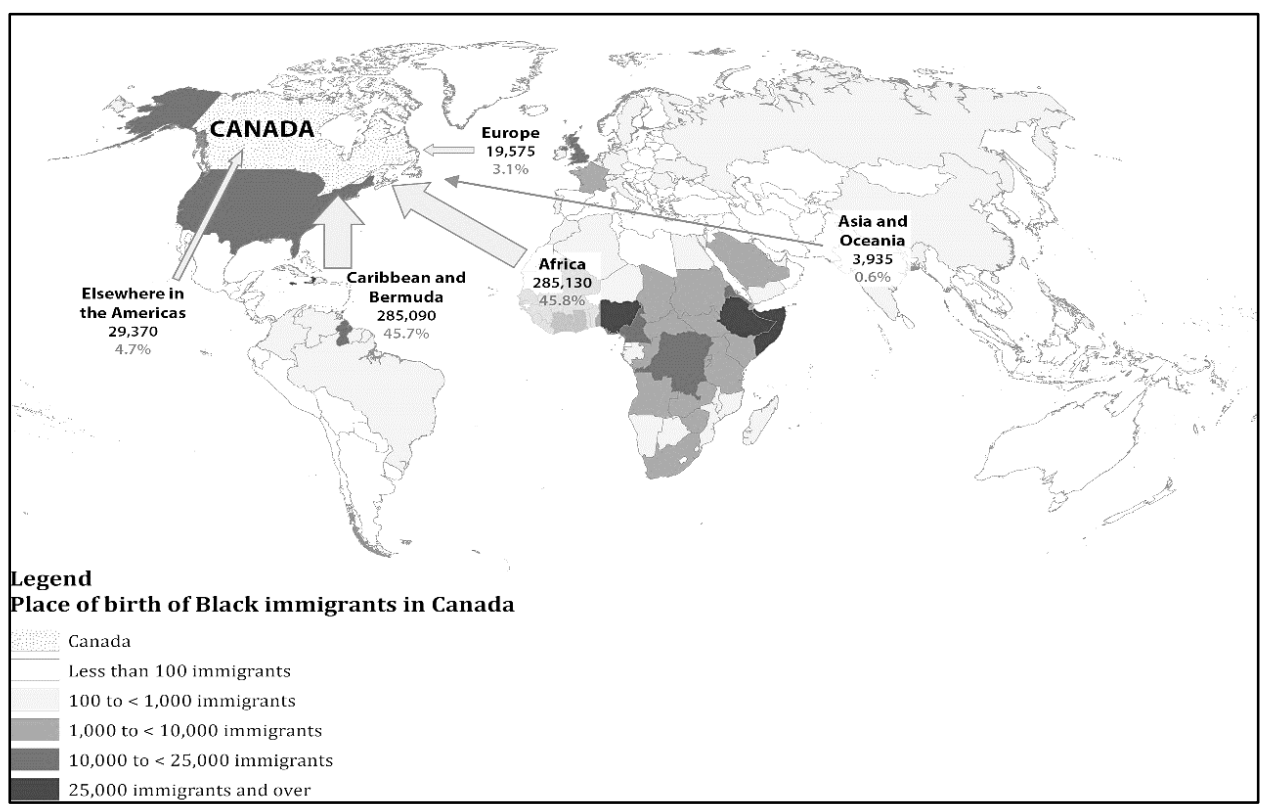

Figure 2. The place of birth of Black immigrants in Canada

Source: Statistics Canada (2016)

Figure 2 shows the place of birth of Black immigrants in Canada. As far as the top ten sources of immigration from Africa to Canada is concerned, Egypt ranked in the $1^{\text {st }}$ place with 4,823 permanent residents in Canada, followed by Morocco with 3,629, Algeria (3,247), Nigeria (3,042), Cameron (2,042), Ethiopia $(1,740)$, Tunisia (1,474), South Africa (1,359), Democratic Republic of the Congo $(1,252)$, and Somalia with 1,129 permanent residents (Hornsby, 2013).

\section{Methodology}

The study sample comprised of 56 participants who were interviewed one-onone, or as a part of a focus group, to discuss their experiences with resettlement and integration challenges. All subjects gave their informed consent for inclusion before they participated in the study. Data used in this research come from transcribed stories gathered through intensive interviews with 26 African Canadian migrants, and three focus groups with 30 participants, 10 participants in each focus group, representing three Ontario cities of Ottawa, Toronto, and Kitchener. The study covered the period from March 2013 to 2017. Using the grounded theory (GT) method interviews were transcribed, coded, categorised, and analysed.

The interviews explored the viewpoints of the participating migrants on how they have dealt with resettlement challenges and the manner in which they 
resolved these challenges. Interviews included written field notes, observations, and one-on-one conversations with the participants. This process also included sound-recording tapes and field notes (Turner, 2010). The information collected was subsequently transcribed, and the data were classified, coded, and interpreted in line with the GT methodology. In sum, the qualitative design of grounded theory first proposed by Charmaz (2006) and extensively used in sociology was adopted. Charmaz' (2006) first work, leading to the development of this method, involved research on dying hospital patients; it used the constant comparative method, which became a crucial element in what has become known as grounded theory (Sbaraini et al., 2011).

The process is defined as an inductive reasoning process emanating from a corpus of information that facilitates the development of a theory (Charmaz, 2006). Participants in this study self-identified as African, using a primordial linkage to Africa as their home of origin. These participants have lived in Ontario for 3 to 20 years. In order to participate in the study, all individuals had to meet the following screening criteria: (1) self-identifies as an African migrant and (2) lives in Ontario for the last five years.

\section{Coding and analysis}

The role of the researcher was to facilitate the conversation and record the experiences of the participants' stories. The challenge for the researcher was how to access others' perceptions carefully, observe their actions, and assign meaning to their language regarding cultural affiliation. As Turner (2010) discussed, social objects, such as ideas, language, actions, symbols, physical objects, and identities, do not provide inherent meaning. This idea was further supported by Denzin (2007) in his discussion of grounded theory and the politics of interpretation, which gives researchers wide latitude in utilising grounded theory as a research method. The interview data were labelled, allowing categories along with their properties and dimensions to emerge. The second phase was the axial coding, in which connections were made between categories to identify conditions that led to the development of these categories and the circumstances in which they appeared. The third phase of the analysis involved selective coding, in which the main category to be used was identified (Turner, 2010).

The main category was then compared and related to the other categories, and the storyline was validated against the data. A series of memos then formed the storyline. Any gaps in the story were filled by returning to the participants for additional information. For this purpose, MS Word 2010 was used to code keywords in participants' transcribed interviews and the initial codes were subsequently colour-coded in clients' stories and distributed words along with developed concepts of what they stand for as categories. Triangulation, constant comparisons, and the interrelation of concepts, categories, and memos have led to three key themes. This process has helped in providing a sequence of steps of data analysis throughout the research analysis and in keeping the information 
flow and line of thoughts focused, as it was a considerable undertaking framing the entire process from initial coding to the development of the storyline.

\section{Results}

Three themes have emerged from participants' perceptions, as they discussed their experiences with the challenges of immigration, integration, and settlement process since they arrived in Canada. They have shared stories about their ordeal, how they dealt with it, their coping mechanisms, and the impact of these experiences on their health and well-being. Participants were assigned pseudonym names to conceal their identity and any ethical implications with confidentiality. The study themes are categorised under (1) information and referrals services, (2) motivation and feelings of demotion, and (3) psychosocial health and well-being. These themes are further discussed in the following sections.

\section{Information and referral services}

The success of migrants arriving in Canada highly depends on the level of information available in their community and referrals to the public services, as well as private employment support and social services provided by the government of the day, to help its new citizens effectively integrate into their country of resettlement. This is one of the themes that emerged from participants' experiences concerning access to support programs, policies, and requirements set by public and private institutions utilised since their arrival to Canada from the country of origin, or refugee or displaced person camps. They have discussed procedures and conditions that were considered prerequisites that immigrants must meet before being recognised as desirable candidates to participate in support programs, as presented by Ferrer et al. (2012).

To help illustrate this further, Hassan stated:

Since my arrival in Canada, I was referred to employment programs that are in place for people who understand the Canadian labour market requirements and culture. I was looking for programs that help immigrants to work in their specialisation. I was promised that my language ability and work experience in my country would land me a job in my field in Canada. I later learned that it is quite difficult for people coming with overseas training, education, and work experience to secure employment in their fields in Canada regardless of your score results in immigration point systems. I am not sure why.

(Male, Age 35: Focus Group)

Similarly, Suzanne said:

The province of Ontario should set up programs that help immigrants integrate into their profession, a program that would start with personal assessment at early stages 
when the immigrant arrives in Canada. We need programs that would prepare us for Canadian workplace culture, professional colleges, and expectations, such as job placement and customised training to work in the fields of profession. Such customised arrangements would give us exposure to workplace culture and would enhance our personal ability to pass interviews.

(Female, Age 28: Interview)

Participants voiced that experience gaps were often perceived by policymakers as personal deficits when, in fact, these gaps were a matter of previous work experience obtained in the country-of-origin and educational background being inappropriately assessed and recognised. Nonetheless, it is difficult to find programs that help with the integration opportunities or mentorship in mainstream Canadian institutions, allowing participants to gain important workplace culture knowledge and communication skills. For obvious reasons, those in charge of immigration programs prefer investing time into promoting and preparing mainstream human resources for career development and future economic advancements, as they are considered the best fit to the workplace culture (The Globe \& Mail, 2012). As Mariam explained:

...to apply for promotions, I was asked for three references from previous employers with whom I had no personal or professional connection or have built any social relationships beyond work. Social ties are considered significant assets and take precedence over skills and experience. Mainstream society prefer to relate to people they know, and would support those they think are good cultural and social fit. These are personal factors that are rare to find among new Canadian with a different cultural and ethnic background like me.

(Female, Age 40: Focus Group)

Jacob added:

When you go to community centres as a newcomer to seek information, they treat you as a person who is not intelligent. Instead of listening to your questions, and asking about your interests and what you have done so far, they will assume that they know all answers to what you need and what you should do. I don't think they don't like me, but it seems like they are following a manual or system that is in place for answering any questions from immigrants. I told her I am a post-secondary graduate from South Africa and that I have finished my programs in English, but still, I get those instructions in a slow, repetitive way as if she was talking to a kindergarten child.

(Male, Age 34: Focus Group)

\section{Motivation and feelings of demotion}

Participants shared their frustrations with the quality of information and mismatched programs they were referred to by professionals due to lack of effective customised programs (Ferrer et al., 2012). This theme emerged from participants' concerns and emotional reactions to the complicated process they 
have encountered and the coping mechanisms they employed to help them deal with these experiences.

As Moses explained:

The method of social and support services has been developed to create a lot of barriers for migrants in the City of Ottawa, as it has been designed for the mainstream society regarding accessibility, eligibility, and delivery of the programs and services. This kind of practice in services provision or support has created a systemic barrier to tools and support services required to help me integrate into the mainstream society. The government needs to develop more accessible and appropriate social and employment services that address specific needs of migrants, and in particular the racialised migrants.

(Male, Age 51: Interview)

Migrants perceived the lack of services and social support programs as barriers to achieving their social and economic integration goals, allowing them to break the cycle of poverty and start a new life in Canada (Legomsky, 1993). Such experiences led to feelings of discouragement and frustration. Those who were hired in a lower position or worked for minimum wage with higher credentials attained back home have expressed strong feelings of demotion. That was the case both among professionals who worked in lower entry jobs in their profession and among those who worked in a different trade unrelated to their qualifications and work experience (Madut, 2013).

John shared:

A person will notice that there is no hope in this country once it is too late. People always try their best to accomplish their goals here in Canada, but it usually takes years before they understand that they have wasted their time.

(Male, Age 51: Focus Group)

Adam recalled:

Even though I had acquired Canadian education and experience, I still struggled to develop a network and contacts for employment leads, a simple task which I found very difficult to accomplish as a Black, African Canadian in Canada. I was also competing for jobs with people born in Canada who had experience and networks and understood social contacts.

(Male, Age 44: Interview)

\section{Ukowa stated:}

I always feel like a loser for being here without a job and unable to raise a family. I am thinking of moving back to Thailand to follow my friends who have left Canada to settle there. I heard they are doing well, helping people, and are not willing to come back to Canada.

(Male, Age 27: Focus Group)

In-depth research showed that African Canadian migrants come to Canada are young and healthy individuals and can still be considered as such within five 
years of their arrival in Canada (Mackinnon, 2016). Even so, policymakers in Canada have failed to capitalise on such able and healthy human resources by investing in effective immigration programs and social support services for immigrants. Migrants directly correlate their resettlement challenges with psychosocial health and well-being.

\section{Psychosocial health and well-being}

The discussion under this theme was based on the participants' perceptions on how the challenges of social, cultural, political, and economic integration in their new society had impacted their health, social relations, and social well-being.

These challenges were discussed by Utiem as follows:

I came to Canada with a medical degree from Egypt. I have worked hard to pass the Canadian equivalencies test, doing low-paid jobs on the side while taking care of my family. After ten years of unsuccessful attempts to secure employment in my field, I lost my family and my health. I think my case would have been different if I came here young and without family. I appreciate being a Canadian citizen, but don't know why I am here and what would this country benefit from me?

(Male, Age 48: Interview)

In this case, individuals who possess advanced skills and qualifications from Canada or back home preferred to work overseas, where their training, education, and skills were recognised and applied. These issues have created cycles of secondary migration and instability (Winkelmann, 2001). However, participants sensed it brings back a sense of personal accomplishment and selfworth.

Susanne stated:

I still believe that Canada has excellent values that I share; however, I do not want to live here poor forever . . . . I have gained a Master's degree from Canada and have learned to speak French, so I think my skills would be competitive in Africa. Things are easy back home, but being a Canadian, I was able to access not-for-profit organisations that have accepted my qualifications, skills, and experience. I was also treated with respect among the members of my community. For me, it was all about giving back to my community.

(Female, Age 37: Focus Group)

Adam also commented:

I was looking for employers who are receptive to working with racialised migrants. Later, I found that it was difficult to find such employers that would allow me to reach my full potential with my skills and education. I then applied to international organisations and found a job overseas with the UNDP. I left my children back in Canada as I fear for their safety. It is frustrating, but an alternative is to accept abuse of welfare staff and live under their mercy. (Male, Age 57: Interview) 
Kofi remarked:

... I think they discriminate against us more than other racialised groups in Ontario . . . . I think policymakers are not aware of our situation because people don't complain and no one thinks Africans matter as much as anybody else. I am a post-secondary graduate from the UK with a degree in engineering. Due to my age, I am unable to do manual jobs I used to do for survival. I guess my useful life and energy was traded for safety and peace. (Male, Age 35: Interview)

Simani muses:

...still there is a hope for the new generation in Canada, known as a colour-blind generation. This young generation doesn't care where people come from, which makes me feel that my grandkids would live in a racist-free Canada. But right now, forget it; there will be no change. I also think that as a parent ... I started to pass my frustrations to children because I believe that I have failed and that children should do well instead, because they were born here .... I think that was an additional burden that children take on from parents.

(Female, Aged 34: Focus Group)

\section{Discussion}

The social and economic integration barriers and the demanding requirements placed upon the African Canadians, and racialised migrants in general, are perceived as the leading causes of frustration with the system and society (Llácer et al., 2009). With this emotional baggage, any social, community, or integration programs are perceived as ineffective and designed to only serve the interests of the mainstream communities (Llácer et al., 2009).

This cynicism and sense of futility are not surprising, since most of those who have been in Canada for more than 30 years have participated in these programs for a long time without success. The participants in this study also discussed concerns with the lack of early intervention through assessment and referrals to appropriate programs and training geared toward facilitating transition into the society socially and economically. The participants felt that the lack of customised cultural and social programs has let them flounder until they figured it out for themselves.

They declared that community and resettlement programs did not provide a clear understanding of the expectations of the Canadian social norms and mainstream culture that may facilitate an effective integration socially, politically, and economically. Participants also shared that current support programs in Ontario are mainly geared toward understanding the integration process and the requirements for becoming a Canadian citizen, rather than becoming a productive contributor to society. Therefore, they felt inadequate and unable to comprehend the complicated process and overcome the endless hurdles and barriers to success in the Canadian society. 
The socio-cultural realities of the integration process and the many and ambiguous requirements placed on African Canadian migrants have created a perception that having Canadian skills or experience may reduce prejudice when competing for jobs with people having the same Canadian qualifications. As explained, it is relatively accurate that recognition of Canadian qualifications and abandonment of foreign credentials has improved the racialised migrants' chances of securing jobs through work placement and internships (Madut, 2013, 2016). Nonetheless, having a Canadian experience in the case of racialised migrants cannot lead to an equal status with Canadian-born mainstream residents, as most employers would still prefer Canadian-born candidates with the same qualifications because of such factors as cultural familiarity, gender, business experience, and age differences (Girard \& Bauder, 2007).

In this context, participants discussed the inadequacies of provincial and municipal support programs designed to help migrants effectively integrate into Canadian society. One notable shortcoming was the lack of customised support programs geared toward the social and economic needs of African Canadians and racialised migrants. Moreover, programs lack resources, such as staff members competent to deal with barriers to employment specific to racialised migrant professionals and cultural variations (Dharssi, 2016). Participants thought that individuals working in these programs should have more integrity, professional expertise, and the real-world knowledge needed to maximise migrants' abilities to effectively integrate and resettle within the Canadian society socially, politically, and economically.

For example, lack of early interventions in areas such as information, customised resettlement training, economic resources and support, housing, as well as protectionism, as evident in the practices of unions and regulatory bodies, remains a significant challenge for migrants' integration process in Ontario (Llácer et al., 2009). These also include professional associations, and the discrimination apparent in the unwillingness of federal, provincial, and municipal institutions to welcome ethnic migrants to practice while supported and mentored by mainstream professionals (Madut, 2016).

Further, the licensing process that helps in accessing economic well-being through sustainable employment was characterised as costly and time-consuming, involving multiple exams and a residency requirement, which made it nearly impossible to fulfil (Dharssi, 2016). For example, those who were not successful in securing jobs in their field of specialisation had to accept entry-level, low paying positions not usually taken by their Canadian-born counterparts with the same skills and qualifications (Llácer et al., 2009).

The resettlement challenges have created cycles of relocation among disadvantaged African Canadian migrant groups between municipalities and provinces. The reason for movements was not only to improve economic wellbeing or personal advancement. Instead, the focus was on alleviating poverty and temporarily re-establishing personal or family finances, i.e., reducing debt (Madut, 2016). Moreover, changes in the global socioeconomic development and the political environment in regional countries or the countries of origin have 
attracted some professionals to go to work in these countries or to go back home (Takenaka, 2007). The opportunities for working overseas or returning home attracted men more than women.

As a result, African women have suddenly found themselves single mothers, and having to cope alone with parenting, work, and discipline of dependent(s), especially young children (Abrams, \& Curran, 2009). These women were also often denied social services and access to community programs, as they are still registered as married instead of single-mothers (Smith-Carrier, 2017). Consequently, these women have given up their dreams of pursuing their rights to learn and work in the profession of their choice. Instead, they are forced to engage in community businesses, such as restaurants and convenience stores, or technical and labour-related jobs (NARCC, 2017).

The active social and economic integration of African Canadians into Canadian society will require early sociocultural exposure and knowledge of the way the political institutions work. Practically, this could be achieved through efficient social community programs, internships, and mentorship. This would be added value if Canadian institutions were willing to accept migrants to join their institutions to practice and be mentored by mainstream Canadian professionals. It does not make sense to give potential immigrants priority admission to Canada and tell them that their skills are needed, only to abandon them into a complicated process in which they endure systemic racism and protectionism and wherein jobs and access to economic opportunities are reserved for mainstream Canadian-born professionals (Madut, 2016).

Economic protectionism and culture of favouritism were some of the integration barriers that hindered the resettlement of the migrants that took part in this study, who cited the additional requirements and hurdles, the detrimental wording of foreign credential assessments, complicated testing and requirements that only favour the mainstream Canadians. These hurdles were ubiquitous, including the requirements of regulatory bodies, professional colleges, and even union affiliation. These also included rejections associated with the biased assessment of migrants' experience and qualifications (Erel, 2010).

Since policymakers and institution leaders are members of the mainstream society, the study participants suspected that racial, ethnic, and cultural biases influenced their professional judgments and decisions. Abolishment of such systemic barriers will improve access to the socioeconomic and cultural integration of African Canadians in particular, and the racialised Canadians in general. The policymakers depend heavily on the regulatory bodies for credential assessment and interpret this as an accurate indication of the candidates' ability to function in their field or profession (Madut, 2016). This type of evaluation and credential assessments are ineffective, except for the minimal confirmation of the authenticity of degrees and the degree-granting institution. 


\section{Conclusion}

The challenges of integration and resettlement process have led to social isolation and economic marginalisation perceived by migrants as a by-product of chronic unemployment, settling for dead-end jobs and cycling through employment, social services and skills development programs until retirement (Stewart et al., 2011). These include frustrated migrants because of the years they invested in the resettlement process and socioeconomic integration. Further, integration failure was also perceived as the cause of permanent marginalisation due to lack of participation in economic and social activities since arriving in Canada (Stewart et al., 2011). These have created a sense of mistrust, isolation, and disappointment with the system and integration programs. Consequently, dealing with personal issues overtakes the focus on a resettlement process.

Finally, ongoing feelings of disappointment and betrayal gradually led to frustration and mistrust in the system and support programs. As this study has shown, the lack of effective settlement services, social support, and bureaucracy are the main obstacles to individual socioeconomic integration. Therefore, migrants questioned professionals' knowledge, judgment, and competence and subsequently discounted or ignored their advice (Stewart et al., 2011).

In short, hardships and poverty have created social conditions, which were perceived as elements that forced migrants to consider an alternative approach to earning a living, such as taking retraining, accepting survival jobs, relocating to other municipalities, leaving their families in Canada to seek employment overseas, or returning to their countries-of-origin. These were also described as factors that affected psychosocial health and well-being.

\section{References}

Abrams, L.S. and Curran, L. (2009), "And you're telling me not to stress?' A grounded theory study of postpartum depression symptoms among low-income mothers", Psychology of Women Quarterly, vol. 33, no. 3, p. 351-362.

Beach, C.M., Worswick, C. and Green, A.G. (2011), Toward improving Canada's skilled immigration policy: An evaluation approach, CD Howe Institute.

Charmaz, K. (2006), Constructing grounded theory: A practical guide through qualitative analysis, CA: Sage, Los Angeles.

Charmaz, K. (2009), "Shifting the grounds: Constructivist grounded theory methods" in J.M. Morse, P.N. Stern, J. Corbin, B. Bowers, K. Charmaz and A.E. Clarke (eds.), Developing grounded theory: The second generation, CA: Left Coast Pres, Walnut Creek, p. 127-193.

Denzin, N.K. (2007), "Grounded theory and the politics of interpretation" in A. Bryant and K. Charmaz (eds.), The Sage handbook of grounded theory, Sage, London UK, p. 455-468.

Dharssi, A. (2016), Skilled immigrants wasting their talents in Canada, Calgary Helard, viewed 13 December 2018, https://urlzs.com/TMCzJ. 
Statistics Canada (2005), Ethnic Diversity Survey (EDS) 2002: Public Use Microdata File and Documentation, 2005001 - ARCHIVED, viewed 22 December 2018, https://urlzs.com/5YGdK.

Erel, U. (2010), "Migrating cultural capital: Bourdieu in migration studies", Sociology, vol. 44, no. 4, p. 642-660.

Ferrer, A.M., Picot, G. and Riddell, W.C. (2014), "New directions in immigration policy: Canada's evolving approach to the selection of economic immigrants", International Migration Review, vol. 48, no. 3, p. 846-867.

Girard, E.R. and Bauder, H. (2007), "Assimilation and exclusion of foreign trained engineers in Canada: Inside a professional regulatory organization", Antipode, vol. 39, no. 1, p. 35-53.

Global Genealogy (1992), Ontario Counties and Townships, viewed 17 April 2019, https://urlzs.com/cF49o.

Creese, G. (2018), "'Where are you from?' Racialization, belonging and identity among second-generation African-Canadians", Ethnic and Racial Studies, p. 1-19.

Hornsby, D. (2013), Top 10 Sources of immigration from Africa to Canada, viewed 17 April 2019, https://urlzs.com/hiE9m.

Hou, F. (2004), Recent immigration and the formation of visible minority neighbourhoods in Canada's large cities, Statistics Canada, Ottawa.

Legomsky, S.H. (1993), "Immigration, equality and diversity", Columbia Journal of Transnational Law, vol. 31, p. 319.

Llácer, A., Del Amo, J., Garcia-Fulgueiras, A., Ibanez-Rojo, V., Garcia-Pino, R., Jarrin, I. and Rodríguez-Arenas, M.A. (2009), "Discrimination and mental health in Ecuadorian immigrants in Spain", Journal of Epidemiology E Community Health, vol. 63, no. 9, p. 766-772.

Mackinnon, M. (2016), Canada's approach to migration health, viewed 24 December 2018, https://urlzs.com/KzM1B.

Madut, K. (2013), "Ethnic migrants: Perspectives on support programs, employability and resettlement challenges in Ottawa, Canada, International", Journal of Contemporary Research, vol. 3, no. 10, p.113-120.

Madut, K. (2016), "How do racialized migrants cope with challenges of labor market integrations and resettlement?", Amsterdam Social Science, vol. 7, no. 1, p. 93-110.

Mullings, V., Morgan, A. and Quelleng, K. (2016), "Canada the great white north where anti-Black racism thrives: Kicking down the doors and exposing realities", Phylon, vol. 53, no. 1, p. 20-41.

NARCC (2017), Racial Discrimination in Canada, viewed 24 December 2018, https://urlzs.com/nKnpi.

Ontario Human Rights Commission (2018), Black and indigenous children overrepresented in Ontario Child-Welfare System in Ontario: Report, viewed 22 December 2018, https://urlzs.com/AKJ5a.

Sbaraini, A., Carter, S.M., Evans, R.W. and Blinkhorn, A. (2011), "How to do a grounded theory study: A worked example of a study of dental practices", $B M C$ Medical Research Methodology, vol. 11, no. 1, p. 128. 
Schroeter, S. and James, E. (2015), "We are here because we are Black: The schooling experiences of French-speaking African Canadian students with refugee backgrounds", Race Ethnicity and Education, vol. 18, no. 1, p. 20-39.

Smith-Carrier, T. (2017), "Reproducing social conditions of poverty: A critical feminist analysis of social assistance participation in Ontario, Canada", Journal of Women, Politics E Policy, vol. 38, no. 4, p. 498-521.

Social Planning Council of Ottawa (2009), Immigrants' economic integration: Successes and challenges, viewed 7 March 2019, https://urlzs.com/gcGzv.

Statistics Canada (2006), Community profile, viewed 20 December 2018, https://urlzs.com/vd5A9.

Statistics Canada (2007), The African Community in Canada, viewed 9 December 2018, https://urlzs.com/udHSg.

Statistics Canada (2019), Diversity of the Black population in Canada: An overview, viewed 17 April 2019, https://urlzs.com/tu4MV.

Steward, G. (2010), Wasted potential: Students and new Canadians talk frankly about the impact of the economic downturn, viewed 17 February 2011, https://urlzs.com/9zu5z.

Stewart, M., Shizha, E., Makwarimba, E., Spitzer, D., Khalema, E.N. and Nsaliwa, C.D. (2011), "Challenges and barriers to services for immigrant seniors in Canada: 'You are among others but you feel alone'", International Journal of Migration, Health and Social Care, vol. 7, no. 1, p. 16-32.

Takenaka, A. (2007), Secondary migration: Who re-migrates and why these migrants matter, viewed 20 December 2018, https://urlzs.com/bLM31.

The Globe \& Mail (2012), Rethinking immigration: The case for the 400,000 solutions, viewed 21 December 2018, https://urlzs.com/rCXbU.

Turner III, D.W. (2010), "Qualitative interview design: A practical guide for novice investigators", The Qualitative Report, vol. 15, no. 3, p. 754-760.

Winkelmann, R. (2001), "Immigration policies and their impact", International Migration: Trends, Policy and Economic Impact, vol. 1. 